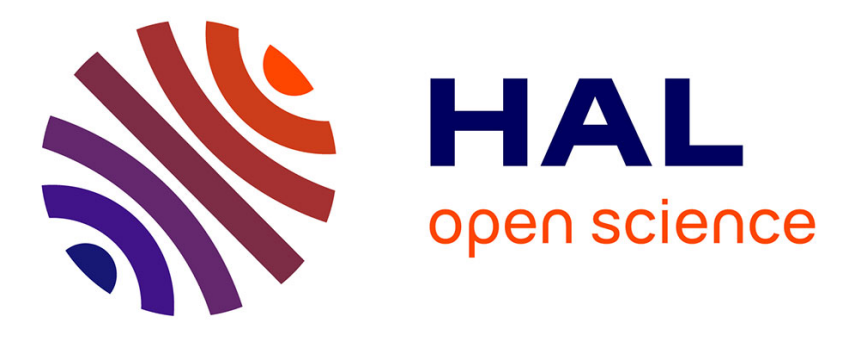

\title{
Corona discharges with water electrospray for Escherichia coli biofilm eradication on a surface
}

Zuzana Kovalova, Magali Leroy, Michael J. Kirkpatrick, Emmanuel Odic, Zdenko Machala

\section{- To cite this version:}

Zuzana Kovalova, Magali Leroy, Michael J. Kirkpatrick, Emmanuel Odic, Zdenko Machala. Corona discharges with water electrospray for Escherichia coli biofilm eradication on a surface. Bioelectrochemistry, 2016, 112, pp.91-99. 10.1016/j.bioelechem.2016.05.002 . hal-01317619

\section{HAL Id: hal-01317619 \\ https: / hal.sorbonne-universite.fr/hal-01317619}

Submitted on 18 May 2016

HAL is a multi-disciplinary open access archive for the deposit and dissemination of scientific research documents, whether they are published or not. The documents may come from teaching and research institutions in France or abroad, or from public or private research centers.
L'archive ouverte pluridisciplinaire HAL, est destinée au dépôt et à la diffusion de documents scientifiques de niveau recherche, publiés ou non, émanant des établissements d'enseignement et de recherche français ou étrangers, des laboratoires publics ou privés. 


\title{
Corona discharges with water electrospray for Escherichia coli biofilm eradication on a surface
}

\author{
Zuzana Kovalova a,b,*, Magali Leroy ${ }^{\mathrm{b}}$, Michael J. Kirkpatrick ${ }^{\mathrm{b}}$, Emmanuel \\ Odic $^{\mathrm{b}}$, Zdenko Machala ${ }^{\mathrm{a}}$ \\ ${ }^{a}$ Faculty of Mathematics, Physics and Informatics, Comenius University in Bratislava, \\ Mlynská dolina, 842 48 Bratislava, Slovakia \\ ${ }^{b}$ GeePs / Group of electrical engineering - Paris, UMR CNRS 8507, CentraleSupélec, \\ Univ. Paris-Sud, Université Paris-Saclay, Sorbonne Universités, UPMC Univ. Paris 06, \\ 3 \& 11 rue Joliot-Curie, Plateau de Moulon 91192 Gif-sur-Yvette CEDEX, France
}

\begin{abstract}
Low-temperature plasma (cold), a new method for the decontamination of surfaces, can be an advantageous alternative to the traditional chemical methods, autoclave or dry heat. Positive and negative corona discharges in air were tested for the eradication of 48-hour Escherichia coli biofilms grown on glass slides.

The biofilms were treated by cold corona discharge plasma for various exposure times. Water electrospray from the high voltage electrode was applied in some experiments. Thermostatic cultivation of the biofilm, and confocal laser scanning microscopy (CLSM) of the biofilm stained with fluorescent dyes were used for biocidal efficiency quantification.

Up to $5 \log _{10}$ reduction of bacterial concentration in the biofilm was measured by thermostatic cultivation after exposure to both corona discharges for $15 \mathrm{~min}$. This decontamination efficiency was significantly enhanced by simultaneous water electrospray through the plasma. CLSM showed that the live/dead ratio after treatment remained almost constant inside the biofilm; only cells on the top layers of the biofilm were affected. DAPI fluorescence showed that biofilm thickness was reduced by about $1 / 3$ upon exposure to the corona discharges with electrospray for $15 \mathrm{~min}$. The biofilm biomass loss by about $2 / 3$ was confirmed by the crystal violet assay.
\end{abstract}

Keywords: Bacterial biofilm, Corona discharge, Non-thermal plasma, Confocal microscopy, Fluorescence, Water electrospray

PACS: 87.18.Fx, 87.64.mk 52.80.Hc, 87.64.kv, 


\section{Introduction}

Bacterial contamination of surfaces is a common problem in hospitals, the food industry, water distribution systems, etc. Nosocomial infections (NI), or so-called hospital acquired infections are responsible for infecting $2-11 \%$ of the patients admitted to the hospital in European Union (EU) and approximately 37000 deaths/year are caused directly by NI in the EU 27 and contribute to an additional 111000 deaths/year. Escherichia coli is one of the most frequently isolated strains from all infection sites in health care facilities [1].

Bacteria on surfaces exist predominantly in the form of biofilms. Microbial biofilms are populations of microorganisms concentrated at an interface (usually solid-liquid) and encased in a hydrated matrix of exopolymeric substances (EPS), polysaccharides, and proteins that are produced by the resident microorganisms [2]. EPS protects cells from the outer environment and facilitates cell-to-cell communication (quorum sensing) [3]. Quorum sensing is required for biofilm differentiation [4], it coordinates gene expression and regulates a diverse array of physiological activities [5]. Bacteria in the biofilm are protected from harsh conditions (high temperature, low pH, ultraviolet radiation, dehydration, etc.), and therefore are more resistant than their planktonic (suspended cells) counterparts [3]. In order to avoid using toxic chemicals or high concentrations of antibiotics to achieve the desired decontamination efficiency in biofilms, a search for new alternative methods of decontamination is required; one of these is low-temperature plasma.

A plasma is defined as a macroscopically neutral ionized gas. Most plasma found in nature exists at high-temperature and is in thermodynamic equilibrium. In this article, the focus will be on non-thermal plasma or so called non-equilibrium or low-temperature (cold) plasma. In cold plasma, the temperature of electrons is high, while the temperature of heavy particles (atoms, molecules, and ions) remains close to ambient. This type of plasma can be generated at atmospheric pressure [6, 7]. Low-temperature plasmas studied under laboratory conditions are typically generated by electrical discharges in

\footnotetext{
*Corresponding author

Email address: kovalova@fmph.uniba.sk (Zuzana Kovalova)
} 
helium [8] or argon $[9,10]$ with admixtures of reactive gases such as oxygen or water vapor, [11, 12] or they can be directly generated in air [13, 14, 15, 16]. In cold non-thermal atmospheric pressure plasma sources, the major active biocidal agents are reactive neutral species (reactive oxygen and nitrogen species, when plasma is produced in air), UV-Vis radiation, and charged species (electrons and ions) along with the corresponding electromagnetic fields [17].

Non-thermal plasma at atmospheric pressure is well-suited for decontamination of thermally sensitive surfaces because the bulk temperature remains close to ambient. Its bactericidal effects have been previously tested on a wide range of bacterial species - planktonic bacteria [18, 19, 20, 21, 22, 23], spores $[21,24,25,26,27,28]$ or bacterial biofilms [29, 30, 31, 32, 33, 34, 35, $36,37,14,38,39,40]$. Thanks to the ease of use of plasma on target surfaces, the first plasma medicine applications appeared in dermatology for wound healing [10, 41] and blood coagulation [42], in dentistry [43, 44] for root canal disinfection [45], and in dental aesthetics for tooth whitening [46].

To increase the production and amounts of the reactive neutral species, water can be added to the discharge, in the form of water vapor (as mentioned before) or as fine liquid droplets electrosprayed from the high-voltage electrode. The electrospray effect emerges when the liquid flowing out from a capillary is exposed to high electrical potential. A "Taylor cone" is produced and the droplets of liquid emerging from its tip being charged are thus accelerated by the electric field $[47,48,49,50]$. The electrosprayed water brings more complexity to the discharge chemistry and its interaction with bacteria. The effect of water electrospray combined with corona discharges has been previously studied in our group $[47,48,51]$ and applied to polymer surfaces contaminated by biofilms and spores $[13,52]$ and to water disinfection $[15,53]$. In this paper, we investigate the impact of water electrospray and polarity of the air corona discharge on 48-hour Escherichia coli biofilm. The biofilm decontamination, thickness reduction, and biomass loss are evaluated by various microbiological and fluorescent microscopy methods.

\section{Materials and methods}

Non-thermal (cold) plasma generated by both positive corona (PC) and negative corona $(\mathrm{NC})$ discharges in air were applied for the eradication of Escherichia coli biofilm formed on glass surfaces (cover slides). The effect 
of the water electrospray combined with the discharge on its bactericidal efficiency was also tested.

\subsection{Experimental set-up and discharges}

Corona discharges in atmospheric pressure air were generated in an experimental set-up consisting of a needle-to-plane electrode system placed in a discharge chamber in open air. The needle electrode was a sharp or a clipped hypodermic syringe needle connected to a DC high-voltage (HV) power supply. Opposite the needle HV electrode, a copper plate was grounded through a $50 \Omega$ resistor. The treated biofilm samples on glass cover slides were placed on the grounded electrode, $5 \mathrm{~mm}$ from the HV electrode. Some experiments were performed with sterile distilled water electrosprayed onto the sample through a hollow clipped HV needle electrode; this was in turn supplied to the needle by pumping with a NE-300 SyringePump (Figure 1). The electrical characteristics of the discharges were measured as follows: the applied voltage with a Tektronix P6015A HV probe connected to the needle electrode, and the discharge current by measuring the voltage across the $50 \Omega$ grounded resistor. Both probes were connected through coaxial cables to a Tektronix TDS 2024 digital oscilloscope for signal recording and storage.

Corona discharges of both polarities were operated in the configuration detailed above. Positive corona (PC) was supplied with a voltage up to $+9 \mathrm{kV}$ and formed streamers with frequencies ranging from 10 to $20 \mathrm{kHz}$ and maximum current pulse amplitudes up to $10 \mathrm{~mA}$ (corresponding to a mean input power $\mathrm{P} \approx 100 \mathrm{~mW}$ ). With water electrospray the pulse frequency was lowered to $10 \mathrm{kHz}$, although the current amplitude was slightly increased but remained under $50 \mathrm{~mA}(\mathrm{P} \approx 200 \mathrm{~mW})$. Negative corona (NC) was supplied with a minimum voltage of $-9 \mathrm{kV}$ and current pulses with frequencies ranging from 0.5 to $2 \mathrm{MHz}$ and amplitudes of $-1 \mathrm{~mA}$ were observed $(\mathrm{P} \approx 300 \mathrm{~mW}$ ). With water electrospray, the pulse frequency was lowered to $200-500 \mathrm{kHz}$ and and the current amplitude increased to $-10 \mathrm{~mA}(\mathrm{P} \approx 400 \mathrm{~mW})$. More details on the discharge experimental conditions can be found in [13].

\subsection{Bacterial samples}

Escherichia coli strain BW25113 F+ [BD792 derivative, rrnB, DElacZ4787, $\mathrm{H} s d \mathrm{R} 514, \mathrm{DE}(\operatorname{ara\mathrm {BAD}}) 567, \mathrm{DE}(r h a \mathrm{BAD}) 568, r p h-1]$ was used to form a biofilm on glass cover slides $(2 \mathrm{~cm} \times 2 \mathrm{~cm} \times 15 \mu \mathrm{m})$ on the bottom of a homemade 6-well plate for 48 hours at $30^{\circ} \mathrm{C}$. A stationary phase culture grown in Miller's modified Luria broth (LB) $\left(37^{\circ} \mathrm{C}\right)$ was diluted by $1 / 100$ in buffered 


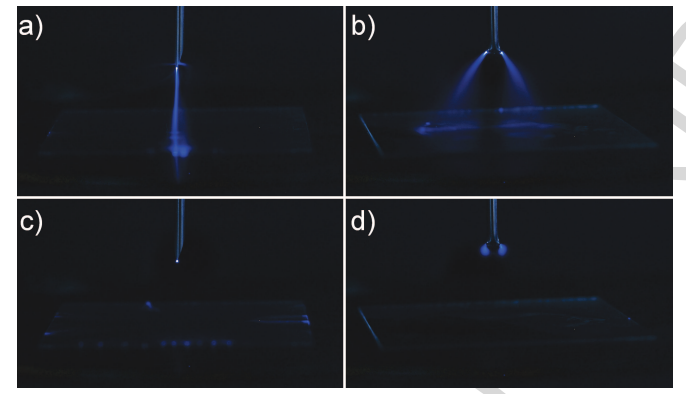

Figure 1: Photographs of the DC corona discharges in air with a hypodermic injection needle as HV electrode (clipped for water electrospray b, d) and a glass cover slide on a copper grounded electrode: a) positive corona, b) positive corona with water electrospray, c) negative corona, $\mathrm{d}$ ) negative corona with water electrospray (4 s exposure time).

(pH 7.4 Phosphate buffered solution) M63 medium (AMRESCO) supplemented with $0.1 \%$ casamino acids and $1 \mathrm{~g} / \mathrm{L}$ glucose. One $\mathrm{mL}$ of this suspension was placed into each well of the 6 -well plate. The samples were incubated without agitation at $30^{\circ} \mathrm{C}$ for 48 hours with media refreshment after 24 hours.

\subsection{Plasma treatment and sample post-treatment}

The biofilms on glass cover slides were taken out from the 6 -well plates after 48 hours. The excess liquid was carefully removed, the samples were dried for up to $20 \mathrm{~min}$ at $35^{\circ} \mathrm{C}$, and then placed onto the grounded electrode inside the discharge chamber and treated with plasma. The control samples were dried using the same procedure but not treated with plasma.

Cultivability was determined by repetitive rinsing of the biofilm with $5 \mathrm{~mL}$ of $0.85 \% \mathrm{NaCl}$ saline solution and scraping with another sterile cover glass. The recovered bacterial cells in the solution were vortexed, serially diluted and spread over LB agar in petri dishes and incubated at $37^{\circ} \mathrm{C}$ overnight, then the bacterial colony forming units (CFUs) were counted.

For imaging using confocal laser scanning microscopy (CLSM), the treated biofilms were stained with a solution of three fluorescent dyes: $1 \mu \mathrm{L}$ Syto9 (5 mmol.L ${ }^{-1}$, Life Technologies), $1.5 \mu \mathrm{L}$ Propidium iodide (PI, 20 mmol.L ${ }^{-1}$, Cayman chemicals) and $5 \mu \mathrm{L}$ DAPI (4',6-diamidino-2-phenylindole, $2 \mathrm{mg} / \mathrm{mL}$, Cayman chemicals) in phosphate buffered saline (PBS, pH 7.4), and incubated for $25 \mathrm{~min}$ in the dark.

CLSM images were acquired with an OLYMPUS IX81 inverted confocal laser microscope. $Z$-stack acquisitions were performed at 16 bits, with di- 
mensions of $640 \times 640 \times 1$ pixels (pixel size $0.33 \times 0.33 \times 0.4 \mu \mathrm{m}$ ), the dimension of the final $z$-stack was $211.2 \times 211.2 \times(0.4 \times \mathrm{N}) \mu \mathrm{m}$, where $\mathrm{N}$ is the number of $z$ optical slices taken. Observed excitation and emission wavelengths (filters) as follows: Propidium iodide: excitation $559 \mathrm{~nm} /$ emission $575-675 \mathrm{~nm}$, Syto9: $473 \mathrm{~nm} / 490-540 \mathrm{~nm}$, DAPI: $405 \mathrm{~nm} / 430-455 \mathrm{~nm}$. Image stacks (.oif or .oib format) were analyzed using Icy 1.6.1.1v [54] from which the sum of intensity in each channel (red - PI, green - Syto9, blue - DAPI) of each optical slice in the stack and three dimensional projections of stacks were obtained.

E. coli BW $25113 \mathrm{~F}+$ in planktonic form was used to obtain the calibration curve for live/dead ratios (according to the supplier manual). Briefly, bacteria in late-log phase were centrifuged to remove nutrient broth and split into two parts: one part with live bacteria diluted in $0.85 \% \mathrm{NaCl}$ saline solution, and the other part in $70 \%$ 2-propanol to kill bacteria. After incubation and washing, the live and dead bacteria were mixed together in various ratios, then stained, and the fluorescence was measured using CLMS. The calibration curve was constructed from the ratios of green (Syto9) and red (PI) fluorescence for the known bacteria live/dead ratios (Figure 2). A real live/dead ratio can be estimated from this curve.



Live bacteria/\%

Figure 2: Calibration curve for bacteria live/dead ratio (ratio of the fluorescence of Syto9 and PI) inside the biofilm measured for the known percentage of live planktonic bacteria (6-10 repeats for each point, mean $\pm 95 \%$ c.i.) 


\subsection{Biofilm biomass evaluation}

Biofilm biomass was evaluated using crystal violet (CV) staining following the established microbiology protocol [55]. The control and plasma-treated biofilms were resealed in the 6 -well plate after treatment and $200 \mu \mathrm{L}$ of $0.1 \%$ crystal violet was introduced into each well. After 10 min incubation, the CV solution was carefully removed by pipetting and biofilms were rinsed with deionized water until the waste liquid was clear. The 6-well plate was dried upside-down overnight at room temperature. When fully dried, $200 \mu \mathrm{L}$ of $33 \%$ acetic acid was added into each well for $15 \mathrm{~min}$ to solubilize the CV, then recovered and diluted in 1/10 deionized water and the absorbance was measured at $550 \mathrm{~nm}$.

\section{Results}

Results of cold plasma application to the biofilm evaluated by thermostatic cultivation and the analysis of biofilm structural changes by CLSM and CV assay are presented here.

\subsection{Thermostatic cultivation}

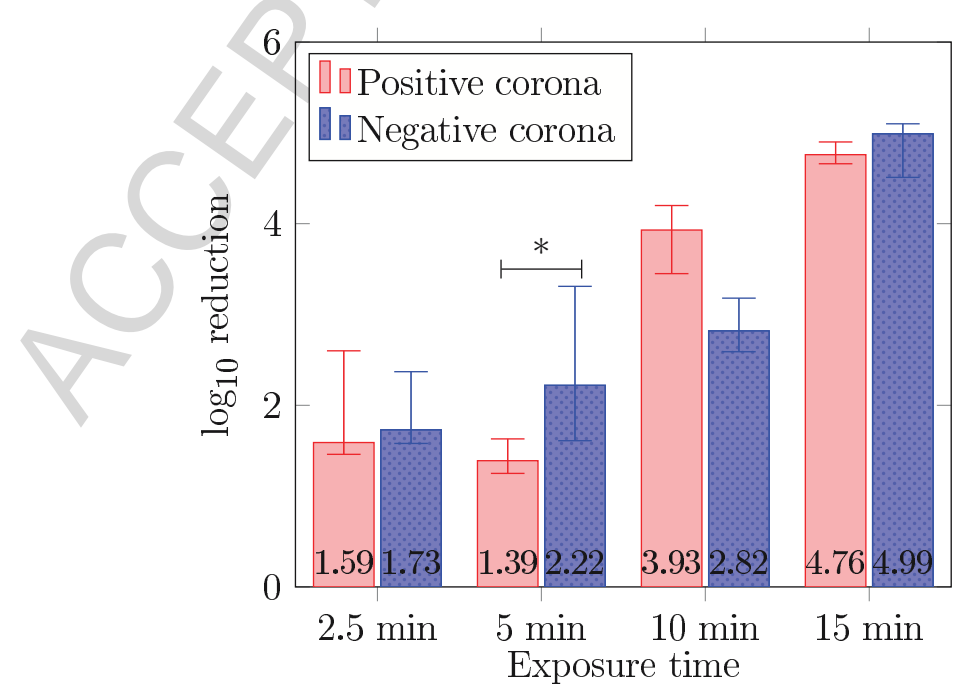

Figure 3: Reduction of bacterial concentration in the biofilm on the cover glass by cold plasma treatment of the corona discharges (medians with IQR - interquartile range, 5-6 independent repetitions, $*$ significant difference between polarities with a probability of error $<0.05)$. 
The reduction in bacterial colony forming units after plasma treatment with variable exposure time $(2.5,5,10$, and $15 \mathrm{~min})$ is presented in Figure 3. The initial bacterial concentration in the biofilm was $3.11 \pm 6.59 \times 10^{6} \mathrm{CFU}$ (colony forming units) per $\mathrm{mL}$ (the biofilms were disrupted and resuspended in $5 \mathrm{~mL}$ of $\mathrm{NaCl}$ solution). In both corona polarities, the decontamination efficiency increased with exposure time and reached up to 4.76 and $4.99 \log _{10}$ reduction for positive and negative corona within $15 \mathrm{~min}$, respectively. No significant differences between positive and negative corona were found, except for 5 min exposure time ( $\mathrm{p}=0.043$, Mann-Whitney test).



Figure 4: Logarithmic reduction of bacterial concentration in the biofilm on the cover glass by corona discharges, effect of water electrospray $0.01 \mathrm{~mL} / \mathrm{min}$ on the sample - hatched bars (medians with IQR, 5-6 independent repetitions, * significant difference between with/without electrospray, a probability of error $<0.05)$.

To evaluate the efficiency of water electrospray through the discharge we present two exposure times: 2.5 and 15 min (Figure 4). For 2.5 min exposure time, the electrospray increased the efficiency from 1.59 to $2.18 \log _{10}$ for PC and 1.73 to $3.41 \log _{10}$ for NC. For negative corona this change was found significant $(\mathrm{p}<0.01$, Mann-Whitney test). For the 15 min exposure time, the difference in efficiency between the plasma only treatment and the plasma with electrospray treatment was found to be smaller, but significant (PC, $\mathrm{p}=$ 0.048, Mann-Whitney test) or marginally significant (NC, $p=0.074$, MannWhitney test). Decontamination efficiency increased from 4.76 to $5.28 \log _{10}$ 
and from 4.99 to $5.4 \log _{10}$ for $\mathrm{PC}$ and $\mathrm{NC}$, respectively, when the water electrospray was used.

\subsection{Confocal laser scanning microscopy}

Images from CLSM contain information on the spatial distribution of the fluorescence from three different fluorescent dyes in the biofilm. DAPI binds preferably to dsDNA and its blue fluorescence is proportional to the amount of the present DNA. In our case DAPI was used to stain all cells in the biofilm. Red PI also stains DNA but does not penetrate through intact cell membranes and is therefore used to stain dead cells, or cells with damaged membranes. Syto9 is a green DNA dye which can penetrate inside all cells. Since PI has a stronger affinity to DNA than Syto9, when both are present in a cell, Syto9 is displaced from DNA by PI and cells are stained red (according to the protocol - L7012 LIVE/DEADB BacLight ${ }^{\text {TM }}$ Bacterial Viability Kit, Molecular Probes).

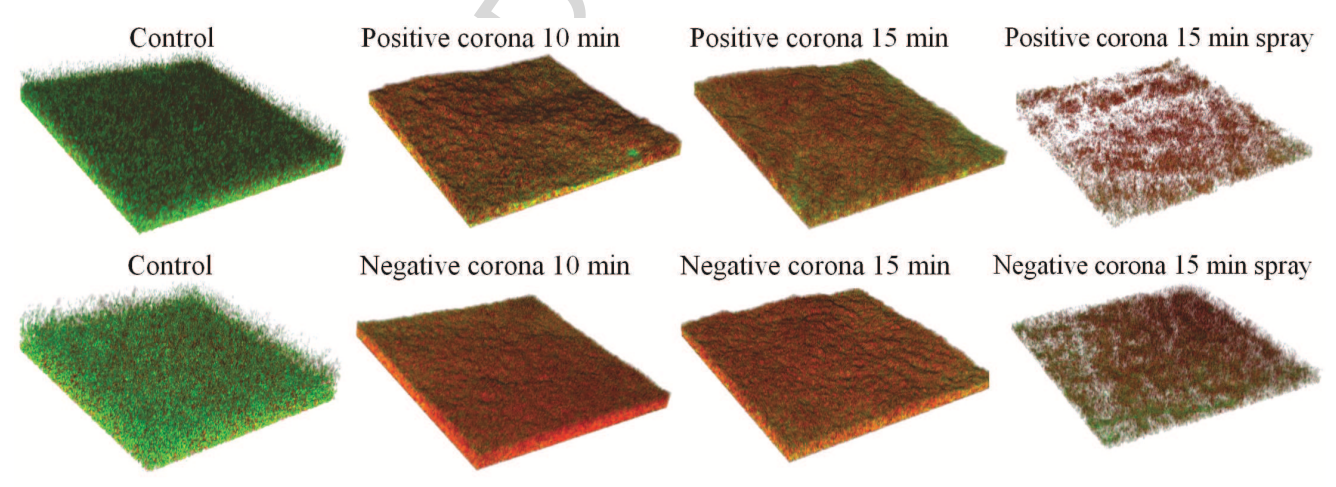

Figure 5: Three-dimensional reconstruction of the biofilm z-stacks from CLSM. First column: sections from control biofilm. Biofilms treated by PC (first row) and NC (second row) for 10, $15 \mathrm{~min}$, and $15 \mathrm{~min}$ with water electrospray. Green fluorescence Syto9 - live bacteria, red fluorescence $(\mathrm{PI})$ - dead bacteria. Magnification $60 \times$, section size $211.2 \times 211.2 \mu \mathrm{m}$.

The fluorescence was acquired from four examined spots on the biofilm: the center and three random places around the center. Examples of reconstructed three-dimensional examined spots $(211.2 \times 211.2 \mu \mathrm{m})$ of the biofilm (the entire biofilm is a $\oslash 12 \mathrm{~mm}$ disc) are presented in Figure 5. From this representation we can see that the plasma treated biofilms contain more dead cells (red) on the top than the controls. The structure of the biofilm also 
changed with plasma treatment: the biofilm seems denser with more compact cellular structure. After plasma treatment with the water electrospray, the biofilm became thinner and patchy.

To quantify the effect of the plasma treatment on the biofilm, the live/dead ratio (Syto9/PI) was calculated. The sums of the red and green fluorescent intensities were measured in each optical slice of the biofilm. The relative values of fluorescence intensity ratios, corresponding to the real live/dead bacteria ratio obtained from the calibration curve (Figure 2), were calculated and plotted along the depth position $z$ in the biofilm (from the bottom $z=0$ to the top of the biofilm - Figure 6 - red). In the control samples (Figure 6 (a)), the live/dead ratio remained constant at $0.9 \pm 0.3$ in the bulk of the biofilm (from $z=0$ to $17 \mu \mathrm{m}$ ), and increased up to $2 \pm 1.5$ toward the biofilm surface $(z=35 \mu \mathrm{m})$. After a $15 \mathrm{~min}$ plasma treatment (with or without electrospray), the mean live/dead ratio remained constant (around $0.7-0.8$ ) for both polarities in the biofilm bulk, and the topmost layers of cells (with the highest live/dead ratio in the control) were lost. This corresponds to the reduction of biofilm thickness which decreased from $35 \mu \mathrm{m}$ (control) down to $23 \mu \mathrm{m}$ by PC with water electrospray, and down to $16 \mu \mathrm{m}$ without water electrospray. For NC, the biofilm thickness was reduced from $35 \mu \mathrm{m}$ (control) down to $13 \mu \mathrm{m}$ with water electrospray, and down to $18 \mu \mathrm{m}$ without water electrospray. 
(a) Control



(b) Positive corona

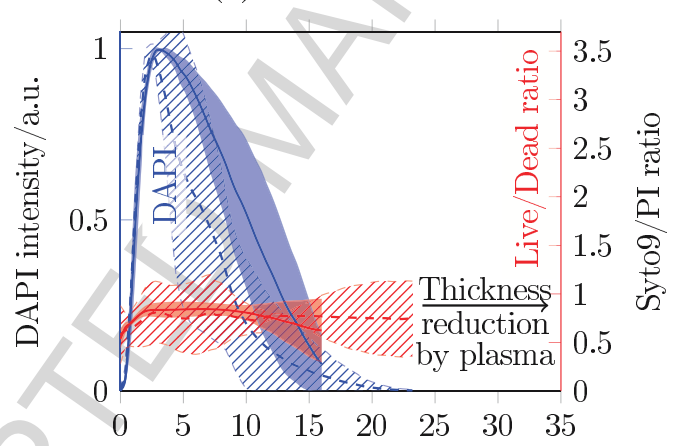

(c) Negative corona

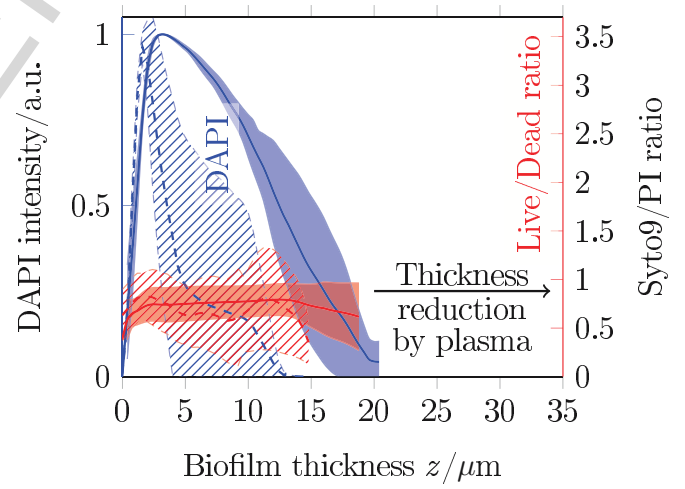

Figure 6: Typical development profile of the total fluorescence intensity of DAPI (blue) and Live/Dead ratio (red) in each optical section of the biofilm. (a) Control samples. (b) Samples exposed to positive corona discharge for $15 \mathrm{~min}$. (c) Samples exposed to negative corona discharge for $15 \mathrm{~min}$. Legend: samples with water electrospray (dashed lines, hatched interval), without electrospray (solid line, solid interval). $z=0 \mu \mathrm{m}$ represents the bottom of the biofilm - glass cover slide. (Data from one experiment, averaged over 4 random places on one sample per condition, areas around the lines represent the data ranges). 
The weak influence of the plasma treatment on the live/dead bacteria ratio in the bulk of the biofilm may indicate that the plasma (active species and radiation) does not penetrate sufficiently inside the biofilm. This can be caused by cellular debris and EPS, which protect the deeper layers of bacteria in the biofilm. The values of live/dead ratio calculated from the total fluorescence of Syto9 and PI (not layer by layer but integrated through all layers) measured on all biofilm samples are presented in Figure 7. These results from all experiments summed together (unlike one specific experiment shown in Figure 6) showed a slight decrease in the live/dead ratio with plasma treatment that is only significant for PC 15 min exposure time with water electrospray. The live/dead ratio decreased from $0.91 \pm 0.02$ (control) to $0.61 \pm 0.03$ in PC, and did not change for NC, at 15 min exposure time and either with or without water electrospray.



Figure 7: Live/Dead ratio calculated from Syto9/PI fluorescence integrated over the entire biofilm thickness for control samples $(\mathrm{n}=21)$, samples exposed for $10 \min (\mathrm{PC}, \mathrm{n}=8$; NC, $\mathrm{n}=12)$, and $15 \mathrm{~min}$ to corona discharge ( $\mathrm{PC}$ and $\mathrm{NC}, \mathrm{n}=12)$, and 15 min exposed to corona discharges with water electrospray $(\mathrm{PC}$ and $\mathrm{NC}, \mathrm{n}=16$ ) (Mean $\pm \mathrm{SD}, *$ significant difference relative to the control, a probability of error $<0.05)$.

The same visualization as for Syto9 and PI (live/dead ratio) was applied for DAPI, for which the sum of the blue fluorescence in the optical slice depends on the depth position in the biofilm (Figure 6 - blue). Using the DAPI staining technique, in the control samples (Figure 6 a) the biofilm reached up to $30 \mu \mathrm{m}$ in thickness. The obtained results with DAPI staining 
confirm the trend in the thickness reduction (biofilm shrinking) observed with the live/dead ratio technique. Again, the stronger effect was obtained for $\mathrm{NC}$ with electrospray.

To better quantify this loss of the biofilm thickness we chose to define the biofilm beginning and end as the slice $z$-positions with $10 \%$ fluorescence compared to the maximal fluorescence observed for all the slices in the $z$ stack. The difference between $\mathrm{z}$ position of the end and the beginning was established as the biofilm thickness. The values of the biofilm thickness were calculated for all $z$-stacks in all biofilms and the result mean values are presented in Figure 8. There is a trend of reduction of the biofilm thickness with the rising exposure time and it is enhanced by adding the water electrospray to the discharge. The only significant difference was found for NC $15 \mathrm{~min}$ with electrospray in comparison with the control sample $(\mathrm{p}<0.05$, ANOVA test - multiple comparisons).

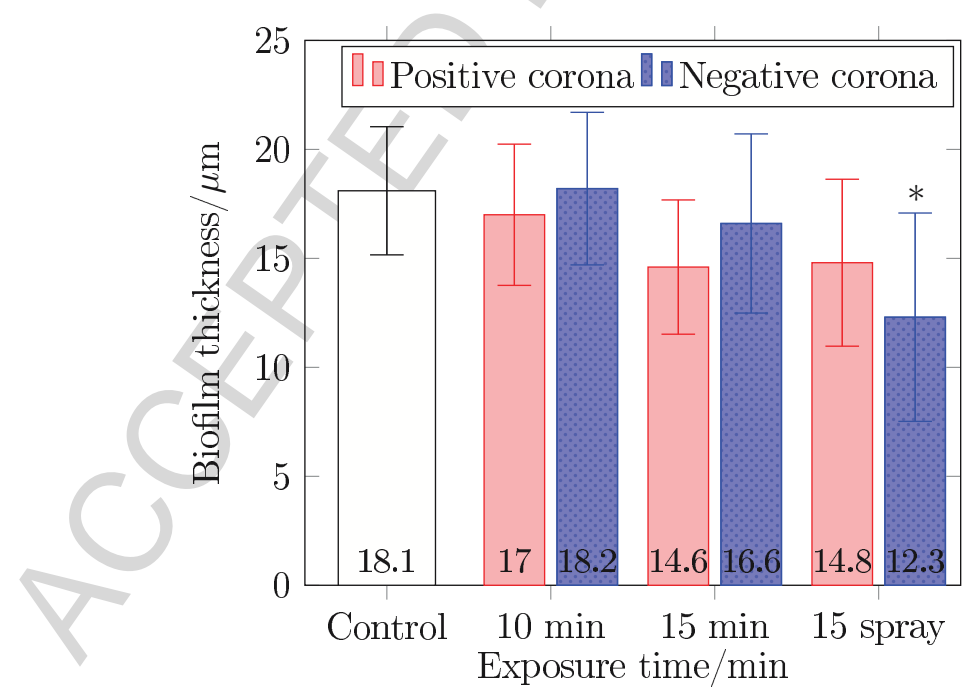

Figure 8: Biofilm thickness calculated from DAPI fluorescence integrated over the entire biofilm thickness for control samples $(n=21)$, samples exposed 10 min $(P C, n=8 ; N C$, $\mathrm{n}=12$ ), and 15 min to corona discharges ( $\mathrm{PC}$ and $\mathrm{NC}, \mathrm{n}=12$ ), and $15 \mathrm{~min}$ exposed to corona discharge with water electrospray ( $\mathrm{PC}$ and $\mathrm{NC}, \mathrm{n}=16$ ) (Mean $\pm 95 \%$ c.i., $*$ significant difference relative to the control, a probability of error $<0.05)$.

\subsection{Biomass evaluation}

The previous results demonstrate the reduction of the biofilm thickness upon corona discharge treatment. However, the observed biofilm thickness 
reduction was not very strong: we suppose that disrupted biofilm layers with dead cells still remained on the top of the intact biofilm. By alleviation (wash-out) of the detached bacteria we can observe the true loss of the biofilm biomass, which could have been underestimated by the presence of these detached but still present cells. The biofilm was stained with crystal violet $(\mathrm{CV})$, incubated and the excess dye was rinsed together with the detached bacteria. The absorbance of solubilized CV was then measured. Considering the dispersion in biofilm (controls) thickness over all experiments, the biomass in plasma treated samples was calculated as the percentage of the control sample absorbance (control sample biomass is equal to 100\%). All experiments shown in Figure 9 were done for 15 min exposure time to the corona discharge. $46.4 \%$ and $33.7 \%$ of the biomass was preserved for PC and $\mathrm{NC}$, respectively, i.e. remained attached to the surface after exposure to the discharges. When the water electrospray was added to the discharge, stronger bacteria detachment occurred and only $36.5 \%$ and $29.5 \%$ of the biomass remained attached to the cover glass in PC and $\mathrm{NC}$ treatment, respectively. All these correspond to significant reductions in comparison with the control samples (ANOVA multiple comparisons $\mathrm{p}<0.05$, for $\mathrm{NC}$ with electrospray $\mathrm{p}<0.01)$.

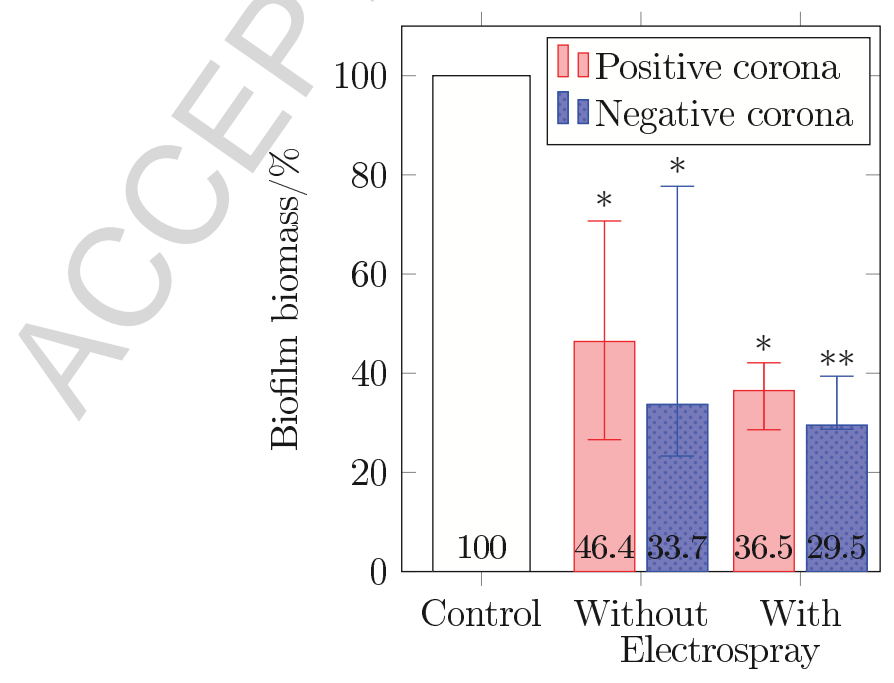

Figure 9: Biofilm biomass calculated as percentage of controls from crystal violet absorbance after 15 min PC and NC treatment with or without water electrospray (Median with IQR, $\mathrm{n}=6$ in each group; $*$, $* *$ significant difference relative to the control, a probability of error $<0.05,<0.01$, respectively). 


\section{Discussion}

In the previous sections, two methods for biofilm viability evaluation were presented: a mechanical disruption of the biofilm followed by a thermostatic cultivation (CFU counts) of bacteria in the resulting solution, and a fluorescent staining and analyzing of the biofilm, layer by layer using the CLMS technique. The reduction of the biofilm thickness and the amount of the attached biomass were investigated by fluorescent DAPI staining, and by colorimetric crystal violet biomass assay. These measurements provided different results but all of them account for different effects of the plasma treatment of biofilms that are discussed in the following sections.

\subsection{Biocidal efficiency}

Thermostatic cultivation (CFU count method) showed a high biocidal efficiency for both polarities of the corona discharge treatment: almost $5 \log _{10}$ reduction of the bacterial population was achieved for a 15 min treatment time. Figure 3 shows a slightly higher (not statistically significant) decontamination efficiency of $\mathrm{NC}$. This was probably caused by higher discharge input power of $\mathrm{NC}(\mathrm{P} \approx 300 \mathrm{~mW})$ in comparison with $\mathrm{PC}(\mathrm{P} \approx 100 \mathrm{~mW})$. The only exposure time where $\mathrm{PC}$ was more efficient than $\mathrm{NC}$ was $10 \mathrm{~min}$; in this case the mean power output of $\mathrm{NC}$ was lower than usual at $230 \mathrm{~mW}$, but remained unchanged for $\mathrm{PC}$. Thus, it can be concluded that $\mathrm{PC}$ was more energetically efficient than NC, since lower energy deposit of $\mathrm{PC}$ provided the same or even higher biocidal efficiency than NC. In PC, positive streamers propagate onto the biofilm surface, so producing in-situ active species (O atoms, OH radicals, and ions) and UV emission (UV-B). Similar neutral active species are also produced by $\mathrm{NC}$, but only in the vicinity of the needle tip (not directly on the biofilm surface); the transport of these shortlived species to the cover glass placed on the plane electrode is supported by the ionic wind, but lower densities can be assumed to be present at the biofilm/gas interface. In addition, relatively stable species such as ozone and nitrogen oxides are produced in both polarities. These species can also contribute to the biofilm treatment.

By adding the water electrospray to the discharge, the decontamination efficiency increased up to $5.5 \log _{10}$ reduction. In this case, $\mathrm{NC}$ was slightly more efficient than PC (but not statistically significant). Energy deposited by the discharge on the sample increased for both polarities in this case, but was two times higher for $\mathrm{NC}(\mathrm{P} \approx 400 \mathrm{~mW})$ than for $\mathrm{PC}(\mathrm{P} \approx 200 \mathrm{~mW})$. 
In the discharge with water electrospray the tip of a hypodermic injection needle was clipped to enable the spray through the discharge. This resulted in the formation of two sharp points from which corona discharge was developed (Figure $1 \mathrm{~b}, \mathrm{~d}$ ). Such a configuration can influence a larger surface of the treated sample, which is visible even from the photographs, and therefore caused higher decontamination efficiency in the experiments with water electrospray. There was also an increase of the power when the water was electrosprayed onto the sample, because a water layer was progressively build up on the cover glass and shortened the distance between the HV and the grounded electrode. Our present results do not clearly show whether the decontamination efficiency increase comes from the higher energy deposit or from other mechanisms such as: increase of the $\mathrm{OH}$ radical formation, rehydration of the biofilm enhancing penetration of active species in its bulk, or others.

CLSM results showed that live/dead ratio development through the biofilms (Figure 6) remains almost constant in the bulk of the biofilm after plasma treatment. The bacteria in the top layers are killed and their cell debris along with the EPS protect the bottom layers of cells by shielding them from direct contact with the plasma (PC). The overall live/dead ratio in biofilms (Figure 7) confirmed that the plasma effect on the biofilm remained spatially superficial. These results contradict those obtained by the thermostatic cultivation. One hypothesis for explaining this contradiction are possible changes in bacterial metabolism after plasma treatment which might induce the viable but nonculturable state (VBNC), as previously hypothesized by Joaquin et al., 2009 [32]. This change can be induced by oxidative stress, or desiccation from the plasma source [35], visible light, starvation, osmotic stress [56] and other adverse conditions. The cytoplasmic membrane of bacteria in VBNC state may remain intact, therefore the PI fluorescent dye would not penetrate inside the cells and they may appear live in CLSM. On the other hand, VBNC bacteria in dormancy state will not proliferate and divide and thus will not form colonies on agar plates, which might cause the apparent high decontamination efficiency evaluated from $\mathrm{CFU}$ plate count. This has been previously reported: plasma treated bacterial cells in a biofilm [32, 35] or a planktonic form $[57,58]$ seem to be dead based on the culturability test, although the fluorescence and metabolic experiments showed that cells were intact and had a functional respiratory system. Therefore these bacteria could be still viable and may preserve their virulence [39]. 


\subsection{Biofilm thickness and biomass reduction}

The measurement of the biofilm thickness by DAPI fluorescent staining (Figure 8) showed a significant reduction for a biofilm treated 15 min by the plasma with electrospray. However this decrease in the thickness was smaller than expected and did not agree well with the CV assay that showed almost $50 \%$ biomass loss (Figure 9). One possible explanation might be that when bacteria are subjected to the stress they can become smaller [59] and more resistant to adverse environmental conditions [60]. The plasma treatment can also affect the EPS of the biofilm, the polymers surrounding the bacterial cells. As was previously reported in Vandervoot and Brelles-Mariño 2014 [39], after longer exposure to the plasma the extracellular polymeric substance is removed or at least reduced. Since crystal violet only detects the attached biomass, the possibility that the observed biomass loss results from the detached biomass cannot be neglected. The plasma treatment impacted the stability of the biofilm by reducing the EPS and the cell adhesion $[35,39]$. Since the biofilm was rinsed during the CV assay, loosely attached and detached bacteria were probably washed away. Rinsing was normally not applied for DAPI visualization, therefore the DAPI biofilm thickness measurements include the detached bacteria and debris in the plasma disrupted biofilm. For this reason, we performed an additional experiment with rinsing of the biofilm after the corona treatment. Both control and plasma treated samples (15 min, electrospray) were rinsed and compared with unrinsed samples (Figure 10) by CLSM live/dead staining. Control samples remained almost intact (visible in Fig. $10 \mathrm{~d}$, side and bottom frames showing the depth profile of the fluorescent signal through the biofilm in corresponding $x$ and $y$ axes), while plasma treated samples were reduced almost to a monolayer of bacteria attached to the glass cover slide. This result confirms that corona discharges were able to disrupt the biofilm structure, which can be then easily detached by washing, while leaving only a monolayer of live single or clustered bacteria attached to the surface of the cover glass. We can assume that by repeating the procedure "plasma treatment + rinsing" we can completely decontaminate and clean the cover glass surfaces.

\section{Conclusion}

Low-temperature (cold) atmospheric pressure plasmas represent a new promising method for surface decontamination, alternative to the traditional 



Figure 10: The biofilm z-stacks from CLSM Syto9/PI staining, 15 min plasma treatment with water electrospray: a) control, b) positive corona, c) negative corona. Second row: d) rinsed control, e) sample rinsed after positive corona treatment, f) sample rinsed after negative corona treatment. Green fluorescence Syto9 - live bacteria, red fluorescence (PI) - dead bacteria. Magnification $60 \times$, section size (xyz) $211.2 \times 211.2 \times 40 \mu \mathrm{m}$. Depth $z$-cross sections of the fluorescence signal through the biofilm are shown in the frames on a side and bottom of each square $\mathrm{x}-\mathrm{y}$ image, corresponding to the z-profiles on $\mathrm{x}$ and $\mathrm{y}$ axes)

chemical and heat treatment methods (autoclave, dry heat, etc.). The decontamination effects of the positive and negative corona discharges in air, examples of low-temperature plasmas, were tested on Escherichia coli biofilm grown for 48 hours on glass slides. The biofilms were treated by the corona discharge plasma for various exposure times from 2.5 to 15 min. Additionally, water electrospray from the HV electrode onto the biofilm samples was used in some experiments. To quantify the biocidal efficiency of the discharges, different methods were used: thermostatic cultivation of bacteria from the biofilm scraped and disrupted in the solution and CFU counting, or confocal laser scanning microscopy (CLSM) of the biofilm stained with fluorescent dyes (Syto9, propidium iodide and DAPI). Bacteria live/dead fluorescence ratio vertical profiles were visualized through the biofilm. The fluorescence intensity of DAPI was used to evaluate the biofilm thickness loss, and the biofilm biomass loss was measured by the Crystal Violet assay.

From thermostatic cultivation of the bacteria from the biofilm, 4.8 and 
$5 \log _{10}$ reductions were observed after 15 min exposure to positive and negative corona discharge, respectively. This decontamination efficiency was significantly enhanced by water electrospray onto the samples to $5.3 \log _{10}$ for positive and to $5.4 \log _{10}$ reduction for negative corona. CLSM showed that the live/dead ratio remained constant in the bulk of the biofilm after treatment, only cells on the top layers were affected by the discharge. Although the live/dead ratio did not decrease, the cells were destroyed and missing. The DAPI staining showed that the biofilm was thinner after plasma treatment (negative corona with electrospray for $15 \mathrm{~min}$ ), with its thickness decreased from $18.1 \mu \mathrm{m}$ in the control samples to $12.3 \mu \mathrm{m}$ after treatment. A substantial biofilm biomass loss was confirmed by the Crystal Violet assay. Additionally, the live/dead staining of the plasma treatment combined with rinsing after the plasma exposure confirmed the substantial reduction of biofilm thickness, which indicates an interesting possibility for potential future applications.

\section{Acknowledgment}

This work was supported by Slovak Research and Development Agency APVV-0134-12 and Comenius University Grant UK/250/2015. Zuzana Kovalova was partly supported by the scholarship of the French government. Special thanks go to Dana Lajdová and Lubomír Tomáška from The Department of Genetics of Faculty of Natural Sciences at Comenius University in Bratislava for CSLM analysis.

\section{References}

[1] European Centre for Disease Prevention and Control, Annual epidemiological report 2014 (2015).

URL http://ecdc. europa. eu/en/activities/surveillance/HAI/Pages/default.aspx

[2] K. Sauer, The genomics and proteomics of biofilm formation., Genome biology 4 (6) (2003) 219. doi:10.1186/gb-2003-4-6-219.

[3] L. Hall-Stoodley, J. W. Costerton, P. Stoodley, Bacterial biofilms: from the natural environment to infectious diseases., Nature reviews. Microbiology 2 (2) (2004) 95108. doi:10.1038/nrmicro821.

URL http://www.ncbi.nlm.nih.gov/pubmed/15040259

[4] J. W. Costerton, P. S. Stewart, E. P. Greenberg, Bacterial biofilms: a common cause of persistent infections., Science (New York, N.Y.) 284 (5418) (1999) 1318-22.

URL http://www.ncbi.nlm.nih.gov/pubmed/10334980 
[5] R. Daniels, J. Vanderleyden, J. Michiels, Quorum sensing and swarming migration in bacteria, FEMS Microbiology Reviews 28 (3) (2004) 261-289. doi:10.1016/j.femsre.2003.09.004.

[6] M. Moreau, N. Orange, M. G. J. Feuilloley, Non-thermal plasma technologies: new tools for bio-decontamination., Biotechnology advances 26 (6) (2008) 610-7. doi:10.1016/j.biotechadv.2008.08.001.

[7] G. E. Morfill, M. G. Kong, J. L. Zimmermann, Focus on Plasma Medicine, New Journal of Physics 11 (11) (2009) 115011. doi:10.1088/1367-2630/11/11/115011.

[8] M. Dang Van Sung Mussard, O. Guaitella, A. Rousseau, Propagation of plasma bullets in helium within a dielectric capillary-influence of the interaction with surfaces, Journal of Physics D: Applied Physics 46 (30) (2013) 302001. doi:10.1088/0022$3727 / 46 / 30 / 302001$.

[9] Z. Kovalova, M. Leroy, C. Jacobs, M. J. Kirkpatrick, Z. Machala, F. Lopes, C. O. Laux, M. S. DuBow, E. Odic, Atmospheric pressure argon surface discharges propagated in long tubes: physical characterization and application to biodecontamination, Journal of Physics D: Applied Physics 48 (46) (2015) 464003.

[10] S. Ermolaeva, A. F. Varfolomeev, M. Y. Chernukha, D. S. Yurov, M. M. Vasiliev, A. a. Kaminskaya, M. M. Moisenovich, J. M. Romanova, A. N. Murashev, I. I. Selezneva, T. Shimizu, E. V. Sysolyatina, I. a. Shaginyan, O. F. Petrov, E. I. Mayevsky, V. E. Fortov, G. E. Morfill, B. S. Naroditsky, A. L. Gintsburg, Bactericidal effects of non-thermal argon plasma in vitro, in biofilms and in the animal model of infected wounds., Journal of medical microbiology 60 (Pt 1) (2011) 75-83. doi:10.1099/jmm.0.020263-0.

[11] J. Winter, K. Wende, K. Masur, S. Iseni, M. Dünnbier, M. U. Hammer, H. Tresp, K.-D. Weltmann, S. Reuter, Feed gas humidity: a vital parameter affecting a cold atmospheric-pressure plasma jet and plasma-treated human skin cells, Journal of Physics D: Applied Physics 46 (29) (2013) 295401. doi:10.1088/0022$3727 / 46 / 29 / 295401$.

[12] J. P. Lim, H. S. Uhm, S. Z. Li, Influence of oxygen in atmospheric-pressure argon plasma jet on sterilization of Bacillus atrophaeous spores, Physics of Plasmas 14 (9).

[13] Z. Kovalová, M. Zahoran, A. Zahoranová, Z. Machala, Streptococci biofilm decontamination on teeth by low-temperature air plasma of dc corona discharges, Journal of Physics D: Applied Physics 47 (22) (2014) 224014.

[14] R. Matthes, C. Bender, R. Schlüter, I. Koban, R. Bussiahn, S. Reuter, J. Lademann, K.-D. Weltmann, A. Kramer, Antimicrobial efficacy of two surface barrier discharges with air plasma against in vitro biofilms., PloS one 8 (7) (2013) e70462. doi:10.1371/journal.pone.0070462.

[15] Z. Machala, B. Tarabová, K. Hensel, E. Špetliková, L. Šikurová, P. Lukeš, Formation of ROS and RNS in Water Electro-Sprayed through Transient Spark Discharge in Air and their Bactericidal Effects, Plasma Processes and Polymers 10 (7) (2013) 649-659. doi:10.1002/ppap.201200113.

[16] E. Sysolyatina, A. Mukhachev, M. Yurova, M. Grushin, V. Karalnik, A. Petryakov, N. Trushkin, S. Ermolaeva, Y. Akishev, Role of the Charged Particles in Bacteria Inactivation by Plasma of a Positive and Negative Corona in Ambient Air, Plasma Processes and Polymers 11 (4) (2014) 315-334. doi:10.1002/ppap.201300041. 
[17] T. von Woedtke, S. Reuter, K. Masur, K.-D. Weltmann, Plasmas for medicine, Physics Reports 530 (4) (2013) 291-320. doi:10.1016/j.physrep.2013.05.005.

[18] G. Kamgang-Youbi, J.-M. Herry, M.-N. Bellon-Fontaine, J.-L. Brisset, A. Doubla, M. Naïtali, Evidence of temporal postdischarge decontamination of bacteria by gliding electric discharges: application to Hafnia alvei., Applied and environmental microbiology 73 (15) (2007) 4791-6. doi:10.1128/AEM.00120-07.

[19] T. Maisch, T. Shimizu, Y.-F. Li, J. Heinlin, S. Karrer, G. Morfill, J. L. Zimmermann, Decolonisation of MRSA, S. aureus and E. coli by cold-atmospheric plasma using a porcine skin model in vitro., PloS one 7 (4) (2012) e34610. doi:10.1371/journal.pone.0034610.

[20] D. Ziuzina, S. Patil, P. J. Cullen, K. M. Keener, P. Bourke, Atmospheric cold plasma inactivation of Escherichia coli in liquid media inside a sealed package., Journal of applied microbiology 114 (3) (2013) 778-87. doi:10.1111/jam.12087.

[21] R. Brandenburg, J. Ehlbeck, M. Stieber, J. Zeymer, O. Schlüter, K.-D. Weltmann, et al., Antimicrobial treatment of heat sensitive materials by means of atmospheric pressure rf-driven plasma jet, Contributions to Plasma Physics 47 (1-2) (2007) 72-79.

[22] K.-Y. Lee, B. J. Park, D. H. Lee, I.-S. Lee, S. O. Hyun, K.-H. Chung, J.-C. Park, Sterilization of escherichia coli and mrsa using microwave-induced argon plasma at atmospheric pressure, Surface and Coatings Technology 193 (1) (2005) 35-38.

[23] R. Sladek, E. Stoffels, Deactivation of escherichia coli by the plasma needle, Journal of Physics D: Applied Physics 38 (11) (2005) 1716.

[24] R. Boucher, State of the art in gas plasma sterilization, Med. Device Diagnost. Indust 7 (1985) 51-56.

[25] S. Hury, D. Vidal, F. Desor, J. Pelletier, T. Lagarde, A parametric study of the destruction efficiency of bacillus spores in low pressure oxygen-based plasmas., Letters in applied microbiology 26 (6) (1998) 417-421.

[26] S. Moreau, M. Moisan, M. Tabrizian, J. Barbeau, J. Pelletier, A. Ricard, Y. LâĂŹH, Using the flowing afterglow of a plasma to inactivate bacillus subtilis spores: Influence of the operating conditions, Journal of Applied Physics 88 (2) (2000) 1166-1174.

[27] M. Heise, W. Neff, O. Franken, P. Muranyi, J. Wunderlich, Sterilization of polymer foils with dielectric barrier discharges at atmospheric pressure, Plasmas and polymers 9 (1) (2004) 23-33.

[28] V. Joubert, C. Cheype, J. Bonnet, D. Packan, J.-P. Garnier, J. Teissié, V. Blanckaert, Inactivation of Bacillus subtilis var. niger of both spore and vegetative forms by means of corona discharges applied in water., Water research 47 (3) (2013) 1381-9. doi:10.1016/j.watres.2012.12.011.

[29] L. van den Bedem, R. Sladek, M. Steinbuch, E. Stoffels-Adamowicz, Plasma treatment of S. mutans biofilms cultured in a simulated dental cavity model, XXVIIth ICPIG, Eindhoven, the Netherlands, 2005.

[30] M. Vleugels, G. Shama, X. Deng, E. Greenacre, T. Brocklehurst, M. Kong, Atmospheric plasma inactivation of biofilm-forming bacteria for food safety control, IEEE Transactions on Plasma Science 33 (2) (2005) 824-828. doi:10.1109/TPS.2005.844524. URL http: //ieeexplore. ieee.org/lpdocs/epic03/wrapper.htm?arnumber=1420625

[31] N. Abramzon, J. C. Joaquin, J. Bray, G. Brelles-Mariño, Biofilm Destruction by RF High-Pressure Cold Plasma Jet, IEEE Transactions on Plasma Science 34 (4) (2006) 
1304-1309.

[32] J. C. Joaquin, C. Kwan, N. Abramzon, K. Vandervoort, G. Brelles-Marino, Is gasdischarge plasma a new solution to the old problem of biofilm inactivation?, Microbiology 155 (2009) 724-732.

[33] M. Hee Lee, B. Joo Park, S. Chang Jin, D. Kim, I. Han, J. Kim, S. O. Hyun, K.-H. Chung, J.-C. Park, Removal and sterilization of biofilms and planktonic bacteria by microwave-induced argon plasma at atmospheric pressure, New Journal of Physics 11 (11) (2009) 115022. doi:10.1088/1367-2630/11/11/115022.

[34] N.-O. Hübner, R. Matthes, I. Koban, C. Rändler, G. Müller, C. Bender, E. Kindel, T. Kocher, A. Kramer, Efficacy of chlorhexidine, polihexanide and tissuetolerable plasma against Pseudomonas aeruginosa biofilms grown on polystyrene and silicone materials., Skin Pharmacology and Physiology 23 (2010) 28-34. doi:10.1159/000318265.

[35] A. J. Zelaya, G. Stough, N. Rad, K. Vandervoort, G. Brelles-Mariño, Pseudomonas aeruginosa Biofilm Inactivation: Decreased Cell Culturability, Adhesiveness to Surfaces, and Biofilm Thickness Upon High-Pressure Nonthermal Plasma Treatment., IEEE transactions on plasma science. IEEE Nuclear and Plasma Sciences Society 38 (12) (2010) 3398-3403. doi:10.1109/TPS.2010.2082570.

[36] X. Pei, X. Lu, J. Liu, D. Liu, Y. Yang, K. Ostrikov, P. K. Chu, Inactivation of a $25.5 \mu \mathrm{m}$ Enterococcus faecalis biofilm by a room-temperature, battery-operated, handheld air plasma jet, Journal of Physics D: Applied Physics 45 (2012) 165205. doi:10.1088/0022-3727/45/16/165205.

[37] F. Marchal, H. Robert, N. Merbahi, C. Fontagné-Faucher, M. Yousfi, C. E. Romain, O. Eichwald, C. Rondel, B. Gabriel, Inactivation of gram-positive biofilms by low-temperature plasma jet at atmospheric pressure, Journal of Physics D: Applied Physics 45 (2012) 345202.

[38] M. Y. Alkawareek, S. P. Gorman, W. G. Graham, B. F. Gilmore, Eradication of marine biofilms by atmospheric pressure non-thermal plasma: A potential approach to control biofouling?, International Biodeterioration \& Biodegradation 86 (A) (2014) 14-18. doi:10.1016/j.ibiod.2013.05.030.

[39] K. G. Vandervoort, G. Brelles-Mariño, Plasma-Mediated Inactivation of Pseudomonas aeruginosa Biofilms Grown on Borosilicate Surfaces under Continuous Culture System., PloS one 9 (10) (2014) e108512. doi:10.1371/journal.pone.0108512.

[40] Z. Xu, J. Shen, Z. Zhang, J. Ma, R. Ma, Y. Zhao, Q. Sun, S. Qian, H. Zhang, L. Ding, C. Cheng, P. K. Chu, W. Xia, Inactivation Effects of Non-Thermal AtmosphericPressure Helium Plasma Jet on Staphylococcus aureus Biofilms, Plasma Processes and Polymers 12 (8) (2015) 827-835. doi:10.1002/ppap.201500006.

[41] G. Isbary, Cold atmospheric plasma for clinical purposes: Promising results in patients and future applications, in: Z. Machala, et al. (Eds.), Plasma for BioDecontamination, Medicine and Food Security, NATO Science for Peace and Security Series A: Chemistry and Biology, Springer, 2012, pp. 311-319.

[42] G. Fridman, M. Peddinghaus, H. Ayan, A. Fridman, M. Balasubramanian, A. Gutsol, A. Brooks, G. Friedman, Blood coagulation and living tissue sterilization by floatingelectrode dielectric barrier discharge in air, Plasma Chem Plasma Process 26 (2006) $425-442$. 
[43] G. C. Kim, H. W. Lee, J. H. Byun, J. Chung, Y. C.Jeon, J. K. Lee, Dental applications of low-temperature nonthermal plasmas, Plasma Processes and Polymers 10 (2013) 199-206.

[44] C. Jiang, C. Schaudinn, D. E. Jaramillo, M. A. Gundersen, J. W. Costerton, A submicrosecond pulsed plasma jet for endodontic biofilm disinfection, in: Z. Machala, et al. (Eds.), NATO Science for Peace and Security Series A: Chemistry and Biology, Springer, 2012, pp. 179-190.

[45] J. Pan, K. Sun, Y. Liang, P. Sun, X. Yang, J. Wang, J. Zhang, W. Zhu, J. Fang, K. H. Becker, Cold plasma therapy of a tooth root canal infected with Enterococcus faecalis biofilms in vitro., Journal of endodontics 39 (1) (2013) 105-10. doi:10.1016/j.joen.2012.08.017.

[46] J. Pan, X. Yang, K. Sun, J. Wang, P. Sun, H. Wu, K. H. Becker, W. Zhu, J. Zhang, J. Fang, Tooth Bleaching Using Low Concentrations of Hydrogen Peroxide in the Presence of a Nonthermal Plasma Jet, IEEE Transactions on Plasma Science 41 (2) (2012) 325-329. doi:10.1109/TPS.2012.2233753.

[47] B. Pongrác, Z. Machala, Electrospraying of water with streamer corona discharge, Plasma Science, IEEE Transactions on 39 (11) (2011) 2664-2665.

[48] B. Pongrác, H. H. Kim, M. Janda, V. Martišovitš, Z. Machala, Fast imaging of intermittent electrospraying of water with positive corona discharge, Journal of Physics D: Applied Physics 47 (31) (2014) 315202. doi:10.1088/0022-3727/47/31/315202.

[49] J. Borra, Y. Tombette, P. Ehouarn, Influence of electric field profile and polarity on the mode of ehda related to electric discharge regimes, Journal of Aerosol Science 30 (7) (1999) 913-925.

[50] J.-P. Borra, P. Ehouarn, D. Boulaud, Electrohydrodynamic atomisation of water stabilised by glow discharge-operating range and droplet properties, Journal of Aerosol Science 35 (11) (2004) 1313-1332. doi:10.1016/j.jaerosci.2004.05.011. URL http://linkinghub.elsevier.com/retrieve/pii/S0021850204000953

[51] H. Kim, Y. Teramoto, N. Negishi, a. Ogata, J. Kim, B. Pongrác, Z. Machala, A. M. Gañán-Calvo, Polarity effect on the electrohydrodynamic (EHD) spray of water, Journal of Aerosol Science 76 (2014) 98-114. doi:10.1016/j.jaerosci.2014.06.002.

[52] Z. Koval'ová, K. Tarabová, K. Hensel, Z. Machala, Decontamination of streptococci biofilms and Bacillus cereus spores on plastic surfaces with DC and pulsed corona discharges, The European Physical Journal - Applied Physics 61 (2013) 24306. doi:http://dx.doi.org/10.1051/epjap/2012120449.

[53] Z. Machala, L. Chládeková, M. Pelach, Plasma agents in bio-decontamination by DC discharges in atmospheric air, Journal of Physics D: Applied Physics 43 (22) (2010) 222001.

[54] F. De Chaumont, S. Dallongeville, N. Chenouard, N. Hervé, S. Pop, T. Provoost, V. Meas-Yedid, P. Pankajakshan, T. Lecomte, Y. Le Montagner, et al., Icy: an open bioimage informatics platform for extended reproducible research, Nature methods 9 (7) (2012) 690-696.

[55] J. H. Merritt, D. E. Kadouri, G. A. O’Toole, Growing and analyzing static biofilms, Current protocols in microbiology (2005) 1B-1.

[56] A. Muela, C. Seco, E. Camafeita, I. Arana, M. Orruño, J. A. López, I. Barcina, Changes in Escherichia coli outer membrane subproteome under environmental con- 
ditions inducing the viable but nonculturable state, FEMS Microbiology Ecology 64 (1) (2008) 28-36. doi:10.1111/j.1574-6941.2008.00453.x.

[57] N. J. Rowan, S. Espie, J. Harrower, H. Farrell, L. Marsili, J. G. Anderson, S. J. MacGregor, Evidence of lethal and sublethal injury in food-borne bacterial pathogens exposed to high-intensity pulsed-plasma gas discharges, Letters in applied microbiology 46 (1) (2008) 80-86. doi:10.1111/j.1472-765X.2007.02268.x.

URL http://www.ncbi.nlm.nih.gov/pubmed/17983430

[58] E. Dolezalova, P. Lukes, Membrane damage and active but nonculturable state in liquid cultures of Escherichia coli treated with an atmospheric pressure plasma jet, Bioelectrochemistry 103 (2015) 7-14.

[59] M. Du, J. Chen, X. Zhang, A. Li, Y. Li, Y. Wang, Retention of virulence in a viable but nonculturable Edwardsiella tarda isolate, Applied and Environmental Microbiology 73 (4) (2007) 1349-1354. doi:10.1128/AEM.02243-06.

[60] R. R. Colwell, Viable but Not Cultivable Bacteria, in: S. S. Epstein (Ed.), Uncultivated Microorganisms, Vol. 10, Springer Berlin Heidelberg, 2009, pp. 121-129. doi:10.1007/978-3-540-85465-4_1. 


\section{Highlights}

- Biocidal effects of air corona discharges were tested on Escherichia coli biofilms.

- Biofilm survival and thickness were evaluated by cultivation and microscopy.

- Cold plasma induced biofilm thinning, biomass reduction, and bacteria inactivation. 